\title{
Reflexões sobre aprendizagem e ensino de física a partir da realidade do Rio de Janeiro ${ }^{1}$
}

\author{
Frederico Alan de Oliveira Cruz \\ Paulo Simeão Carvalho
}

\begin{abstract}
Resumo: A aprendizagem dos alunos presentes nas escolas brasileiras tem se mostrado insuficiente face aos resultados das avaliações nacionais e internacionais, para os diferentes níveis de instrução. Assim, neste trabalhou buscou-se encontrar e compreender as razões para o atual cenário e buscar respostas que possam ajudar a conseguir soluções para o problema. São mostrados como os fatores econômicos e sociais, ligados ao aluno, às questões de infraestrutura na sociedade brasileira e às metodologias de ensino, por parte dos professores, atuam de forma negativa no desempenho escolar. Como tal, apresentamos reflexões sobre a necessidade de mudança nas práticas educativas no ensino das ciências e da Física em particular, bem como no processo de formação dos profissionais de educação, permitindo a eles compreender o cenário educativo onde está inserido.
\end{abstract}

Palavras-chave: Ensino de ciências. Formação. Metodologias.

\section{Reflections on learning and teaching physics from the reality of Rio de Janeiro}

\begin{abstract}
The learning of thousands of students attending brazilian schools, has proved to be insufficient because of the results of the various national and international assessments for different levels of education. In this work we tried to find and understand the reasons for the current scenario and seek for answers that can help to find solutions to this problem. It is shown how economic and social factors related to the student, issues concerning the infrastructure in Brazilian society and the teaching methodologies on the part of the teachers, act in a negative way in the student's performance. So, we present reflections about the need to change the educational practices in the teaching of science and physics in particular, as well as in the process of teacher training, allowing them to understand the educational scenario where they are inserted.
\end{abstract}

Keywords: Teaching science. Training. Methodologies.

\footnotetext{
${ }^{1}$ Os autores agradecem ao Ministério da Educação do Brasil pela oportunidade de realizar este trabalho. O trabalho foi financiado pela Fundação para uma Ciência e Tecnologia, Projeto UID / NAN / 50024/2013.
} 
CRUZ, Frederico Alan de Oliveira; CARVALHO, Paulo Simeão. Reflexões sobre aprendizagem e ensino de física a partir da realidade do Rio de Janeiro.

\section{Introdução}

Apesar dos avanços no acesso às escolas públicas brasileiras e do aumento de número de vagas disponíveis, nas diferentes modalidades de ensino existentes, há um consenso que a educação fornecida por essas instituições é, em algumas situações, de pouca qualidade e/ou descontextualizada da realidade onde os alunos estão inseridos (ALGEBAILE, 2004; RAUTH, 2015).

Percebem-se problemas desde a apresentação e avaliação dos conteúdos fornecidos aos alunos, em que se detectam: aulas descontextualizadas, utilização de livros didáticos de forma quase bíblica e que são colocados como norteadores dos temas a serem abordados em determinada série, programas curriculares que não acompanham as novas tecnologias e/ou as mudanças ocorridas em todo o mundo, inexistência da formulação de processos avaliativos que produzam parâmetros para uma intervenção que potencie a aprendizagem, e até a falta de informação sobre a realidade cognitiva dos alunos (MEGID NETO; FRACALANZA, 2003; PINA, 2009).

Além dos problemas envolvidos diretamente na atividade docente, existem outros fatores que impactam o processo de ensino-aprendizagem, podem ser citados: falta de infraestrutura na maioria das escolas, a violência contra professores e alunos, os baixos salários dos profissionais de educação e também a distância da escola aos locais onde os alunos residem (LOURENCETTI, 2014; MONTEIRO; SILVA, 2015). Todos os fatores somados têm produzido na educação brasileira, principalmente nos últimos anos, um quadro de insucesso que dificilmente será reduzido sem mudanças significativas nos diversos pontos citados anteriormente.

Os atuais índices educacionais, produzidos por agências nacionais e internacionais, mostram que o atual processo de escolarização dos jovens brasileiros não reúne a qualidade necessária para que o país avance em termos tecnológicos e sociais nos próximos anos, sendo fundamental ações que visem a uma melhora significativa na estrutura de formação. Isso fica claro quando avaliamos os números relativos ao Índice de Desenvolvimento da Educação Básica (IDEB), criado pelo Instituto Nacional de Estudos e Pesquisas Educacionais Anísio Teixeira (INEP) em 2007 para ser indicador da qualidade educacional brasileira. Estas informações, obtidas por meio de exames padronizados para alunos do $5^{\circ}$ e $9^{\circ}$ ano do ensino fundamental, bem como a alunos do $3^{\circ}$ ano do ensino médio, revelam um quadro assustador (INEP, 2007). Numa 
escala de zero a dez, dentre os 26 estados brasileiros e o distrito federal, apenas os estados de Santa Catarina e São Paulo apresentaram pontuação média igual ou superior a cinco para as turmas do $9^{\circ}$ ano do ensino fundamental, na mais recente avaliação.

Se particularizarmos o nosso estudo para o estado do Rio de Janeiro, que detém o segundo maior Produto Interno Bruto (PIB) do Brasil, em torno de 460 bilhões de reais no ano de 2016, percebemos que o aporte financeiro disponível não foi suficiente para produzir avanços educacionais relevantes; isto pode ser comprovado pela décima terceira posição entre os entes da federação, com nota igual a 4,4, e com desempenho abaixo da média nacional, que é de 4,5 na avaliação do Índice de Desenvolvimento da Educação Básica (IDEB) (INEP, 2015a; IBGE, 2016).

Mantendo a análise sobre o referido estado, os resultados do Exame Nacional do Ensino Médio, criado em 1998 e que desde 2009 é utilizado pelos alunos para ascender às muitas Instituições de Ensino Superior (IES) do país, são preocupantes. Nas avaliações que testam conhecimentos de linguagens, matemática, ciências humanas, ciências da natureza e redação, que possuem pontuação entre 0 (zero) e 1000 (mil), foi constatado que a metade dos alunos avaliados, oriundos das escolas públicas e privadas de ensino médio localizadas no Estado do Rio de Janeiro, não conseguiram obter nota superior a 600 pontos em qualquer dos itens que compõem a avaliação no ano de 2015 (INEP, 2015b).

Nessa avaliação, os piores desempenhos ocorreram nos conhecimentos ligados aos temas de matemática e ciências da natureza, nos quais a pontuação média gira em torno de $50 \%$ dos pontos possíveis, no qual se incluem, nesse último, questões sobre conhecimentos em Física. Os resultados apresentados pelos alunos durante as avaliações demonstram uma grande fragilidade no conhecimento científico, que possivelmente terá impacto direto no desempenho a obter na formação em nível superior. Além disso, esses mesmos alunos evidenciam um desempenho que permite supor a existência de problemas na forma culta da língua portuguesa. Assim, mesmo com uma pequena generalização, é possível concordar que (BELUCE et al., 2011, p. 8): “[...] o nível de compreensão leitora dos estudantes universitários está aquém do esperado para obtenção e elaboração de conhecimentos necessários no ensino superior”.

Coincidentemente com a afirmação anterior, os cursos de disciplinas introdutórias de cálculo diferencial e integral, nos quais são abordados conceitos importantes para a continuidade nos cursos ligados a ciências exatas, como Meteorologia, Astronomia, Geologia e Engenharia em 
CRUZ, Frederico Alan de Oliveira; CARVALHO, Paulo Simeão. Reflexões sobre aprendizagem e ensino de física a partir da realidade do Rio de Janeiro.

geral, apresentam índices de reprovação acima de 50\% (RAFAEL; ESCHER, 2015). Corroborando a seguinte situação já apresentada em uma realidade: "Os alunos que têm ingressado ao curso de física vêm com uma deficiência enorme de conteúdo matemático e de leitura e interpretação de texto. Isto acarreta ao aluno dificuldade de acompanhamento das disciplinas, o que, inevitavelmente, gera retenção nas diversas séries" (RISSI; MARCONDES, 2009, p. 44).

Essas reprovações, aliadas a outros fatores, são causas, muitas das vezes, das enormes evasões nos cursos de formação superior nas áreas onde são necessários os conhecimentos básicos sobre ciências, matemática e linguagem, esse último com implicação na interpretação correta das questões presentes nas avaliações.

No entanto, o mau desempenho nas avaliações sobre ciências e matemática não ocorre apenas ao nível nacional e tem se repetido ao longo dos anos, nas avaliações promovidas pela Organização para a Cooperação e Desenvolvimento Econômico (OCDE), que ocorrem a cada três anos e conhecidas como Programa Internacional de Avaliação de Alunos (PISA). Nas provas realizadas em 2014, os alunos brasileiros tiveram um percentual de acertos nas questões de ciências de aproximadamente $30 \%$. Na maioria dos estados e no caso específico do estado do Rio de Janeiro, o percentual de acertos foi inferior a esse valor (gráfico 1). Mesmo nas questões com pequena complexidade de resolução, identificadas como aquelas de demanda cognitiva baixa, os acertos dos alunos brasileiros não foram superiores a 45\% (OCDE, 2016).

Gráfico 1 - Percentual de respostas corretas dos jovens brasileiros, por unidade da Federação, para os conteúdos de ciências do PISA.

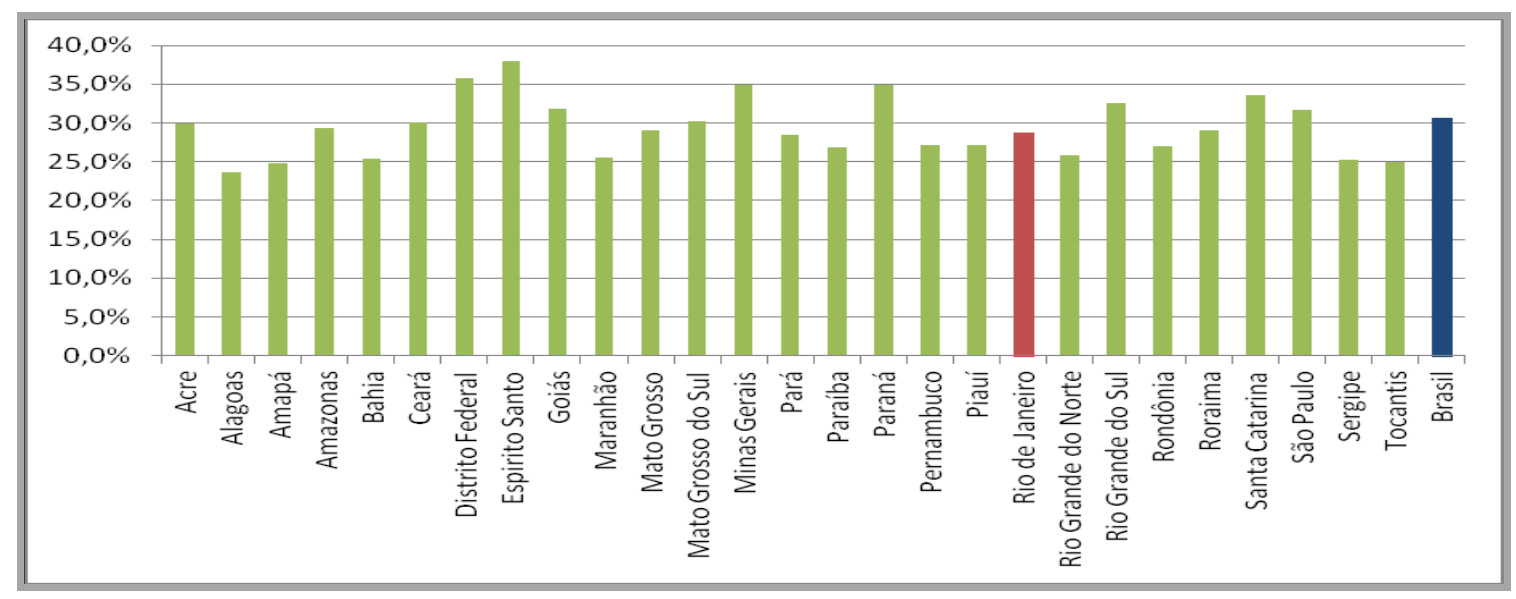

Fonte: OCDE. Organização para a Cooperação e Desenvolvimento Econômico. Brasil no PISA 2015: análises e reflexões sobre o desempenho dos estudantes brasileiros. São Paulo: Fundação Santillana, 2016. p. 52. 
CRUZ, Frederico Alan de Oliveira; CARVALHO, Paulo Simeão. Reflexões sobre aprendizagem e ensino de física a partir da realidade do Rio de Janeiro.

É fato que muito do baixo desempenho, retratado pelos índices mostrados, tem relação direta com as condições sócio econômicas no qual os alunos estão inseridos. No entanto, refletir sobre esses pontos é fundamental para que seja possível qualificar a discussão sobre como possibilitar uma melhora na aprendizagem e com isso no desempenho desses alunos.

\section{A influência dos fatores econômicos e sociais sobre a aprendizagem}

Para compreender todos os fatores que podem influir no desempenho dos alunos nas avaliações e no seu desenvolvimento cognitivo, a condição econômica das famílias dos alunos sempre é um elemento considerado como fundamental, ou como ponto de partida na análise do tema. Sabe-se que crianças e jovens oriundos de famílias em condições financeiras mais precárias apresentam, em média, pior desempenho nos exames do que aquelas em melhores situações financeiras e que um aumento considerável nos salários resulta significativamente num maior desempenho global dos alunos (CRUZ, 2012).

A dificuldade na aprendizagem dos conceitos de ciências, como dos demais conteúdos do currículo escolar, tem como um dos fatores basilares o atraso social das regiões onde muitas das famílias estão localizadas e que coloca diversos jovens em alto grau de vulnerabilidade. Elementos como a equiparação entre o Produto Interno Bruto (PIB) e o Poder Aquisitivo (PA), as médias dos anos de escolarização dos constituintes do núcleo familiar e a relação com a longevidade das pessoas, elementos que constituem o chamado Índice de Desenvolvimento Humano (IDH), apesar de serem importantes para a caracterização das populações podem não dar a informação necessária sobre muitos aspectos ligados ao bem estar social dos indivíduos.

Para ter um retrato fiel da realidade dos alunos que estão inseridos dentro de cidades com construção heterogênea, é importante que sejam levados em conta elementos de bem estar como o acesso ao saneamento básico e a qualidade habitacional. Assim, avaliar apenas o IDH pode fornecer uma visão incompleta, pelo que uma possibilidade é considerar o chamado Índice de Desenvolvimento Social (IDS), que atribui pesos diferentes a certos parâmetros contidos no IDH e insere elementos como os outros dois citados anteriormente (IBGE, 2000; CAVALLIERI; LOPES, 2008).

Ainda que o Rio de Janeiro seja reconhecidamente uma das cidades com maior nível de riqueza do país, é fácil perceber diversos problemas estruturais ainda presentes. Apesar de nos 
CRUZ, Frederico Alan de Oliveira; CARVALHO, Paulo Simeão. Reflexões sobre aprendizagem e ensino de física a partir da realidade do Rio de Janeiro.

últimos anos ter ocorrido avanço no IDH em praticamente todos os bairros da cidade, em virtude do volume financeiro fomentado por uma série de eventos promovidos, como Olimpíadas e Copa do Mundo, as melhorias sociais fundamentais não evoluíram e até diminuíram em algumas regiões.

Num elemento comparativo entre o IDH e o IDS dos bairros existentes na cidade, é facilmente perceptível que o último índice é menor que o primeiro em torno de $25 \%$ (CAVALLIERI; LOPES, 2008, RIO DE JANEIRO, 2009) (gráfico 2), isto é, apesar de em muitos casos existir desenvolvimento educacional e financeiro de muitas famílias, outros elementos que favorecem uma qualidade de vida minimamente razoável ainda são insuficientes (RIO DE JANEIRO, 2009).

Gráfico 2 - Relação entre o IDH e o IDS medidos para os bairros do município do Rio de Janeiro

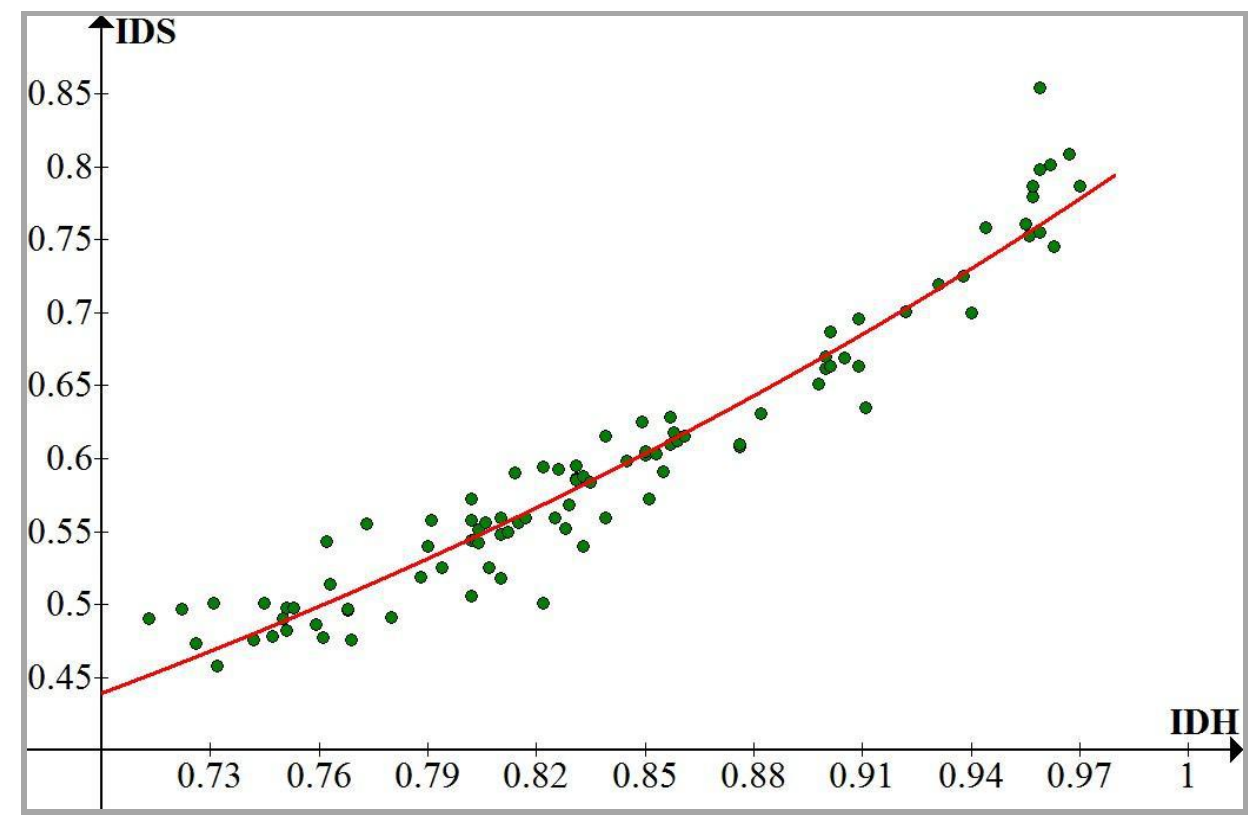

Fonte: CAVALLIERI, Fernando; LOPES, Gustavo Peres. Índice de Desenvolvimento Social - IDS: comparando as realidades microurbanas da cidade do Rio de Janeiro. Rio de Janeiro: Instituto Municipal de Urbanismo Pereira Passos, 2008.

RIO DE JANEIRO. CMRJ - Câmara Municipal do Rio de Janeiro. ANEXO III. 2009. Disponível em: <http://www.camara.rj.gov.br/planodiretor/pd2009/ saudepd/Anexo3_IDH.pdf>. Acesso em: 13 jun. 2018. 
Talvez isso passe despercebido nas avaliações sobre o desempenho dos alunos, mas sabese que condições insalubres podem implicar doenças, baixa qualidade de nutrientes e afetar o desenvolvimento cognitivo dos jovens, com reflexos imediatos no baixo desenvolvimento educacional dos estudantes, mesmo que estes tenham possibilidades financeiras consideradas razoáveis. O impacto dessa realidade é tão grande que tomando, por exemplo, a melhoria dos serviços de fornecimento de água e coleta de lixo, os estudos indicam que os desempenhos escolares são aumentados e a distorção série-idade, que ocorre quando o aluno possui mais de dois anos de atraso escolar, é reduzida (SCRIPTORE; AZZONI; MENEZES FILHO, 2015).

Outro problema que se relaciona com as questões sociais é a falta de condições habitacionais em várias escolas, que em muitas situações não envolve diretamente as ferramentas educacionais disponíveis pelos professores para a realização da sua atividade letiva. Devido ao clima da cidade do Rio de Janeiro, com temperaturas médias durante os períodos matutinos e vespertinos acima dos $30^{\circ} \mathrm{C}$, durante boa parte do tempo de aulas, é fundamental que haja acesso à água potável. No entanto, em muitos casos, a água disponível para as escolas brasileiras em muitas cidades é de baixa qualidade e imprópria para o consumo humano. Isso impacta de forma significativa a atividade de todos os profissionais ligados aos estabelecimentos de ensino e principalmente no aproveitamento escolar dos alunos (LEWIS, 2009, p. 2): “As crianças que não bebem (água) regularmente na escola têm níveis de concentração mais baixos que afetam a sua capacidade de participar nas lições, e finalmente nos níveis de aprendizagem e de êxito".

Se condições de fornecimento de água e saneamento básico têm impacto negativo no contexto educacional, temos ainda que considerar a consequência da violência urbana sobre a vida escolar de milhares de jovens. É comprovado que existe um pior desempenho educacional em locais onde a violência é maior, visto que (MONTEIRO; ARRUDA, 2011, p. 9): “[...] a elevação da criminalidade no município onde a escola se localiza aumenta a probabilidade desta obter maiores indicadores de evasão escolar [...]”.

Sendo assim, numa cidade como o Rio de Janeiro, onde foi constatada uma taxa de homicídios da ordem de quase trinta mortes por cem mil habitantes no ano de 2016, a possibilidade de baixo desempenho e consequente evasão escolar é uma realidade que não pode ser ignorada. A onda de violência estabelecida nas ruas acaba sendo trazida para dentro dos muros da escola, onde começa a valer o medo e uma visão da lei do mais forte, que se reflete 
nesse espaço em atos como: depredação das instalações, violência física, bullying, racismo e xenofobia, bem como a ostentação de símbolos ligados a grupos criminosos.

O impacto da violência, fora e dentro das escolas, pode ser percebido nas avaliações sobre o desempenho escolar, onde aproximadamente $45 \%$ dos alunos das instituições de ensino localizadas nas capitais brasileiras não conseguem se concentrar nos estudos e mais de um terço deles perderam a vontade de ir à escola (AMBROMAVAY; RUA, 2002). É perceptível, pelos resultados em alguns estudos, que existe uma relação direta entre a violência e o desempenho cognitivo dos alunos em situação de risco (GROGGER, 1997; AIZER, 2008). Mesmo que a queda de desempenho seja pequena, em algumas realidades, é fato que a violência, de diferentes formas, e da criminalidade existente são fatores de diminuição do desempenho escolar (CARROLL, 2006).

Assim, a evasão escolar será apenas o retrato final da queda de desempenho dos alunos devido à violência, dentro e fora da escola, acrescentando números aos já quase $6 \%$ de alunos que abandonam a escola devido à violência, produzindo assim uma geração que ficará à margem da sociedade pela falta de formação adequada para seu progresso social (GROGGER, 1997; HURT et al., 2001; ABRAMOVAY; RUA, 2002).

Outro ponto que deve ser levado em conta, além dos já mencionados, é o efeito provocado no desempenho dos alunos associado à acessibilidade à escola, isto é, com disponibilidade de meios de transporte que sejam eficientes para conduzir os alunos até o local onde será realizada sua formação. O que se percebe é que longas distâncias e/ou o excessivo tempo perdido no trajeto residência-escola faz com que os muitos alunos cheguem atrasados às aulas e com muitas horas de jejum, prejudicando a atenção e o interesse pelo que está sendo abordado (MHILIWA, 2015). Em cidades como o Rio de Janeiro, com sérios problemas de mobilidade, é possível que o desempenho dos alunos seja prejudicado por falta de acesso rápido à escola ou pela baixa qualidade do transporte disponível, fatores que agravam o tempo de exposição a assaltos e à violência da cidade.

Diante de tantos problemas a que os alunos estão expostos em seu dia a dia, é fundamental que o professor compreenda a necessidade de uma mudança na forma de ensino de conteúdos e nas abordagens educacionais a adotar em sala de aula. Para isso, ele deve ter consciência que o seu papel é essencial para que ocorra uma mudança no atual sistema educativo de que ele é parte integrante. 


\section{A necessidade de mudança no processo educativo e avaliativo}

As informações fornecidas até aqui nos trazem algumas certezas, uma vez que o atual cenário social não é favorável, pois com um IDH próximo de 0,76 o IDS não ultrapassaria de 0,6 usando uma avaliação grosseira, por meio do gráfico apresentado na Figura 1. Isso mostra que os métodos utilizados na fase de discussão dos temas nas escolas, habitualmente chamados de tradicionais, devem ser revistos, posto que estes consideram por princípio que os alunos têm as condições necessárias para o seu desenvolvimento educacional de forma igualitária, que agora percebemos não ocorrer.

\subsection{Um novo público necessita de novos métodos}

O baixo desempenho em todos os formatos de avaliação registrado para as escolas do Rio de Janeiro está atrelado aos fatores já mencionados anteriormente, indo desde a condição econômica das famílias até ao desenvolvimento estrutural da cidade, que estão entrelaçados de forma muito complexa. Muitos desses elementos não estão ao alcance do professor, mas no entanto o obrigam a buscar técnicas de ensino e aprendizagem que possam minimizar os diversos problemas existentes no cotidiano desses alunos. Uma dessas técnicas é o envolvimento ativo dos estudantes em atividades de aprendizagem em grupo na sala de aula, que lhes faça sentir que o seu contributo é validado pelo professor e pelos colegas, que a sua ideia é discutida pelos pares independentemente de estar certa ou errada e que pode vislumbrar um uso, mesmo que ténue, do conhecimento que adquire nas aulas (SWEET; PELTO-SWEET, 2008). Estudos realizados sobre o impacto da aprendizagem ativa em cursos STEM (Science, Technology, Engineering and Mathematics) mostram que esta metodologia aumenta o desempenho dos alunos relativamente ao método de ensino tradicional e expositivo (FREEMAN et al., 2013).

Outro aspeto a ter em consideração é o papel das experiências laboratoriais na aprendizagem das ciências, em particular no que respeita às ciências experimentais. Estas, em que se incluem as ciências físicas, têm particularidades relativamente a todas as outras, não apenas de conteúdo, mas igualmente históricas. Em termos de conteúdo, os conceitos basilares das ciências físicas são na sua grande maioria do tipo intermédio ou formal (CARVALHO et al., 2013), que de acordo com Cantu e Herron (1978) os exemplos podem ou não ser compreendidos pelos alunos, mas os atributos dos conceitos não são facilmente perceptíveis. Tal significa que 
CRUZ, Frederico Alan de Oliveira; CARVALHO, Paulo Simeão. Reflexões sobre aprendizagem e ensino de física a partir da realidade do Rio de Janeiro.

para além da dificuldade natural da compreensão das ideias em ciências, há ainda que contar com o desenvolvimento cognitivo dos alunos como fator determinante para a sua aprendizagem. Como os conceitos formais apenas são facilmente compreendidos por alunos no estágio piagetiano formal, adivinha-se a dificuldade em ensinar e aprender essas ciências por jovens que ainda não atingiram esse estado de desenvolvimento cognitivo; foi esta a razão que levou Shayer e Adey (1981) a classificar as ciências físicas como "duras” (hard sciences).

Em termos históricos, a evolução da ciência faz-se atualmente de uma forma bem diferente da que ocorreu nos seus primórdios. Na Grécia antiga, a ciência era, sobretudo, naturalista e observacional, importada em registrar os fenômenos e interpretá-los com base numa linguagem comum e não científica (SERZEDELLO, 2012). Ao introduzir a experimentação e o controle de variáveis como características do pensamento científico, Galileu (1564-1642) inaugurou uma época em que a repetitividade e a sistematização das atividades práticas permite a todos os cientistas confirmar os resultados obtidos, introduzindo assim uma prática a que se deu o nome de método experimental. Com base nele, muitos resultados empíricos foram sistematicamente confirmados e passados a leis físicas, num processo inicialmente indutivista, mas que hoje evoluiu para uma sequência de processos indutivista e dedutivista (CARVALHO et al., 2013), resultando num modelo de aquisição de conhecimento que Koponen e Mäntylã (2006) designam por generativo experimentalista. A importância da experimentação é, portanto, amplamente aceita pela comunidade científica atual, mas ainda existe a dúvida se os resultados obtidos na aprendizagem na escola por via experimental são vistos com a devida importância.

Em dois artigos publicados com um intervalo de cerca de 20 anos, Hofstein e Lunetta (1982; 2004) concluem que os laboratórios influenciam fortemente a motivação dos alunos pelas ciências físicas, mas apenas produzem um efeito significativo nas aprendizagens quando é abandonada a repetição ritualística de lista de tarefas a executar, e substituída por abordagens em que cada tarefa é discutida previamente com os alunos e dado um significado científico que vise encontrar respostas, pela investigação, a um problema concreto. Esta visão para um ensino interativo é, também, partilhada por vários autores como Redish (2003), Mazur (1997), Novak et al. (1999), Knight (2004) e Sokoloff, Thornton e Laws (1999-2004), que sugerem o uso da metodologia Inquiry, das simulações computacionais, da aquisição automática de dados, das tecnologias digitais, da abordagem fenomenológica básica e do questionamento conceptual, como ferramentas potenciadoras de uma aprendizagem significativa. 
Independentemente de estarmos em pleno século XXI, as práticas educativas das escolas brasileiras estão ainda pautadas no modelo em que o uso das tecnologias de informação e comunicação (TIC) são, na grande maioria dos casos, meros elementos decorativos. Por outro lado, a existência de recursos digitais (simulações computacionais, vídeos, jogos) não garante, por si só, a qualidade na aprendizagem - esta está fortemente condicionada pelo método de ensino proposto para a exploração desses recursos digitais (CARVALHO; CHRISTIAN; BELLONI, 2013) e pela preparação dos professores em implementar esses recursos na sua prática letiva (QUINTAS; CARVALHO, 2016). Isto, por si só, justifica uma aposta forte na formação inicial e contínua de professores, como prática essencial na mudança sustentada do ensino nas escolas.

Mesmo que alguns destes aspetos já terem sido discutidos por muitos autores, o que ainda vemos nos dias de hoje são práticas letivas onde os pontos necessários para a realização de uma boa discussão física (BYBEE et al., 2008 apud BUABENG, 2015) são pouco ou quase nunca seguidos, percebendo-se o oposto e que permite reescrever essas afirmações como:

a) falta de planejamento das aulas e ausência de propostas que incluam inovações didáticas e/ou sequências com real valor educativo na aprendizagem;

b) pouco ou quase nenhum incentivo por parte dos professores para que todos os alunos participem das discussões sobre os temas da aula, negando assim a possibilidade de um ensino interativo;

c) falta de propostas com caráter inclusivo, não permitindo que alunos com e sem necessidades educativas especiais possam trabalhar de forma colaborativa;

d) avaliações ocorridas em tempos determinados e não de forma continuada, o que incentiva a mecanização de processos (nomeadamente a resolução acrítica de exercícios) e a memorização;

e) pouca diversidade nos instrumentos de avaliação, sendo o(s) "teste(s)" usado(s) como ferramenta (em muitos casos) exclusiva para a classificação dos alunos;

f) falta de recursos e ambiente propício para a aprendizagem científica, nomeadamente ao nível laboratorial;

g) pouco estímulo dos professores para que os alunos possam buscar um comportamento científico em relação ao mundo em que vivem, privilegiando assim $0 \quad$ ensino matematizado e academicamente compartimentado; e

h) pouco uso do potencial das tecnologias digitais como suporte didático da compreensão e mensuração dos fenômenos físicos. 
Uma metodologia de ensino que envolva o aluno, porque ele se sente interessado pelos conteúdos e consegue atribuir um objetivo prático à sua aprendizagem, dá um significado real à presença do aluno na escola, à leitura de textos, à interpretação de fenômenos e ao interesse pela ciência em geral. Isto vislumbra um futuro e portanto, retira o aluno das ruas e da violência, ao mesmo tempo em que lhe proporciona conhecimentos que lhe serão úteis para a procura de emprego, que por sua vez lhe darão estabilidade econômica, entrando assim numa espiral que o fará mudar para um estilo de vida com maior qualidade humana e social.

\subsection{A mudança sobre a avaliação}

Uma avaliação deve incidir sobre as metas de aprendizagem consideradas fundamentais para o conhecimento proposto nessa área e para um determinado nível de instrução. Quando uma avaliação revela um grau de conhecimento dos alunos que não é adequado às necessidades do país ou da exigência tecnológica e social do momento, então existe uma forte possibilidade de os métodos usados na instrução terem que ser alterados. Atualmente, a avaliação dentro das instituições de ensino brasileiras tem sido alvo de estudo por diversos pesquisadores (MENEGUEL; KREISCH, 2009). Em causa está o caráter punitivo da avaliação atual e a sua incapacidade na obtenção de parâmetros para a ação do professor que lhe permita mudar a forma de apresentar o conteúdo aos alunos (CABRAL NETA, 2006; FREITAS; COSTA; MIRANDA, 2014). Isso significa que há necessidade de proceder a uma reformulação não apenas das abordagens letivas, mas também uma redefinição dos parâmetros de aprendizagem e, como tal, do sistema de avaliação. Em conclusão, quando o professor adota uma metodologia de ensino diferente, também tem de alterar a forma de avaliar os alunos.

Avaliar um conjunto vasto de competências dos alunos, nomeadamente ao nível dos conhecimentos conceitual e processual, mas também das componentes atitudinal e axiológico, implica recorrer a ferramentas diversificadas que possam fornecer parâmetros fiáveis para essa avaliação. O emprego de metodologias ativas no processo letivo proporciona momentos de criatividade, de reflexão e de desenvolvimento de capacidades, para usar o conhecimento adquirido em contextos diversos, devendo as atividades propostas em contexto letivo ser alvo de um processo avaliativo que efetivamente reflita o que o aluno sabe e consegue fazer. 
Isto não significa que os testes devam ser eliminados. Simplesmente, o peso dos testes e exames no processo avaliativo deve ser repartido com outros elementos de avaliação a delinear pelos professores, tais como atividades de leitura prévia, trabalhos de projeto e de pesquisa, atividades experimentais reais e virtuais com os respectivos relatórios, análise de vídeos educativos, exploração de simulações computacionais, por exemplo, podendo ser estes avaliados como trabalhos de grupo ou individuais (CARVALHO; PÁRAMOS, 2017). Recentemente, têm surgido várias propostas neste sentido de diversificar as situações de avaliação em contexto letivo (KOSER, 2012; PERRY, 2013; CARVALHO; PÁRAMOS, 2017), que constituem uma boa fonte de informação e apoio para os professores.

Esta forma de avaliação distribuída é mais próxima daquilo que o aluno efetivamente sabe e consegue fazer em termos práticos. Ela reveste-se, assim, de um caráter mais justo e atua como um estímulo para o aluno encarar a escola, não como um lugar punitivo ou de perda de tempo, mas com o potencial formativo e social por ele reconhecido para melhorar a sua qualidade de vida.

A grande questão é que para pensar em novos métodos de exposição e avaliação dos conteúdos lecionados, é necessário que os profissionais saibam buscar novos horizontes educativos. O problema nessa equação é que espera-se uma atuação diferenciada dos profissionais em ensino básico sem que eles tenham sido formados para esse fim; isto é, nos cursos voltados a fornecer a habilitação em licenciatura, as aulas e metodologias de ensino ainda estão presas aos métodos tradicionais.

Se admitirmos que existe uma orientação já estabelecida na formação inicial e continuada dos futuros professores, é possível que elementos como a estrutura dos cursos e o perfil do corpo docente integrante das instituições de ensino superior com responsabilidade nessa formação, sejam pontos importantes que devem ser levados em conta durante essa análise.

\section{Um olhar sobre a estrutura do curso e o corpo docente das instituições formadoras de licenciados: o caso particular da física}

É indiscutível que a qualidade de uma instituição de ensino está fortemente ligada à qualificação do corpo docente que faz parte dela, visto que estes são responsáveis pela formação dos profissionais que daí advêm. No entanto, nos cursos de formação inicial de professores, é 
CRUZ, Frederico Alan de Oliveira; CARVALHO, Paulo Simeão. Reflexões sobre aprendizagem e ensino de física a partir da realidade do Rio de Janeiro.

fundamental que os responsáveis pelas disciplinas da grade curricular possuam o entendimento sobre as reais competências que os alunos (futuros professores) precisam desenvolver, além da capacitação necessária para a atividade letiva no ensino superior. Nesse sentido, um olhar sobre os cursos de formação de licenciados em Física permitirá relacionar a falta de uso de metodologias diferenciadas na educação básica com as características do curso e dos profissionais responsáveis pela formação dos professores, que atuaram no segmento de ensino já citado.

No Estado do Rio de Janeiro existem várias instituições de ensino superior que dispõem, dentro do seu conjunto de cursos, a opção que visa atender aos interessados em obter o grau de licenciado em Física. Quase $60 \%$ desses cursos estão localizados em municípios na região metropolitana do Rio de Janeiro e a maioria sendo oferecida por instituições públicas (MEC, 2017).

Gráfico 3 - Distribuição percentual das instituições que possuem o curso de licenciatura em Física, na região metropolitana do Rio de Janeiro

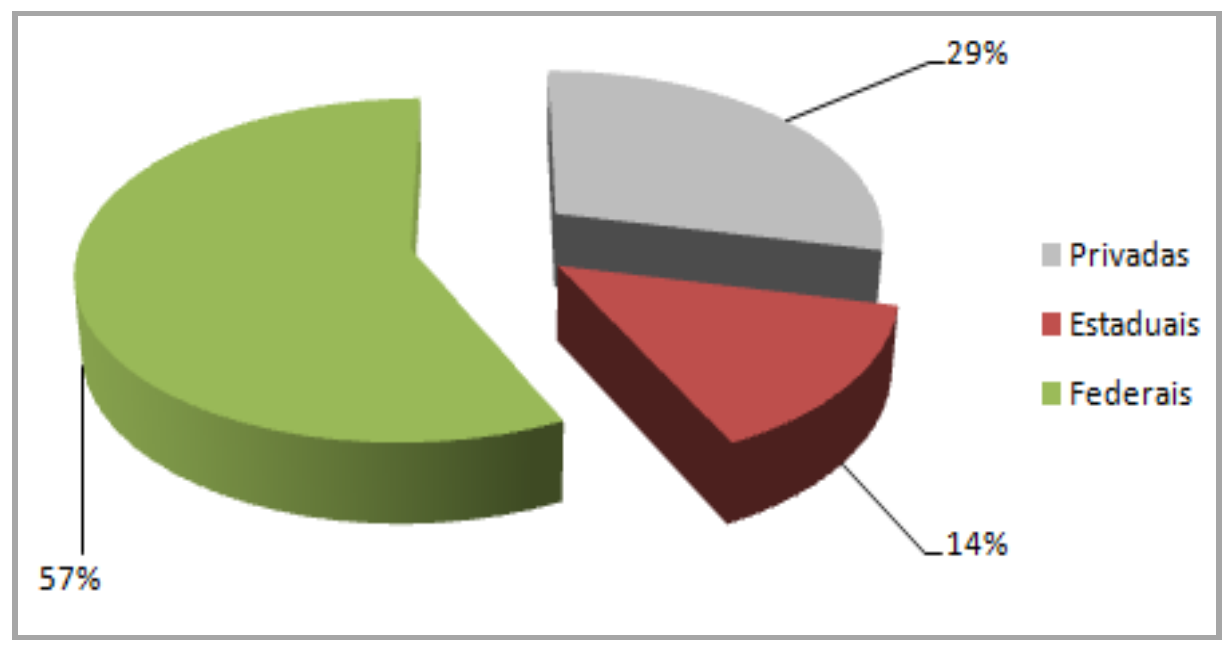

Fonte: BRASIL. Ministério da Educação. Instituições de educação superior e cursos cadastrados. Brasília: MEC, 2017. Disponível em: 〈http://emec.mec.gov.br〉. Acesso em: 5 maio 2017.

Todas essas instituições são reconhecidas pela excelência e tradição na formação de profissionais nos cursos de licenciatura e/ou bacharelado. No entanto, na estrutura desses cursos percebe-se que eles estão subdivididos em cinco grupos básicos de disciplinas com as seguintes características (UERJ, 2017; UFF, 2018; UFRJ, 2017; UFRRJ, 2017): 
- grande carga conceitual em Física, desconectada da atividade na qual os alunos serão formados,

- cunho matemático/computacional;

- conteúdos pedagógicos gerais, habitualmente lecionados por profissionais das áreas de pedagogia, psicologia e sociologia que, apesar de apresentarem conhecimento reconhecido dos referidos tópicos, não permitem a compreensão dos fenômenos naturais que favoreçam uma abordagem dos temas de Física durante as aulas;

- conteúdos especificamente ligados a técnicas de ensino da Física; e finalmente

- conteúdos diversos.

Além de existirem, na estrutura dos cursos, poucas disciplinas que contribuam diretamente para que ocorra uma transposição didática dos conceitos de Física, sabe-se que as aulas nas instituições formadoras têm pouca ou quase nenhuma inovação tecnológica para a apresentação dos temas. Nas habitualmente denominadas aulas teóricas, estas ainda são estruturadas num formato tradicional, sendo muito similares com aquelas apresentadas em nível básico (ZANOTELLO; ALMEIDA, 2007, p. 1), onde o seguimento das aulas se dá: “[...] através de livros didáticos ou apostilas que apresentam um breve resumo das teorias físicas, seguido pela resolução de exercícios, em geral organizados de modo a produzir apenas uma repetição sistemática de procedimentos”.

Nas aulas experimentais, onde deveria haver grande discussão sobre os fenômenos, percebe-se, pelo formato das aulas, que elas são centradas em obter resultados. Ao entrarem nos laboratórios os alunos recebem um roteiro de experimento, que podemos entender como um protocolo de ações, uma "receita" para seguir acriticamente um conjunto de passos para obter um determinado valor para certa grandeza de interesse, que servirá para posteriormente ser produzido um relatório a entregar ao professor responsável (PAZ, 2014).

Essa realidade está ligada a alguns fatores. O primeiro deles tem relação com a falta de vivência de muitos professores das Instituições do Ensino Superior (IES) no ensino básico e das necessidades prementes da profissão, tanto no que diz respeito à sua capacitação para realização das provas de acesso a instituições de ensino como para a sua atividade profissional. Outro ponto está associado ao entendimento equivocado da legislação vigente para a criação de uma grade curricular moderna para a formação de licenciados, impedindo assim que esta seja mais enxuta e eficiente. 
A questão sobre os docentes das IES pode gerar, em um primeiro momento, algum desconforto, mas a sua análise se faz necessária para que seja possível compreender o atual cenário do ensino. Ainda que esses profissionais sejam reconhecidamente bem formados a nível científico e com grandes índices de publicação, em revistas nacionais e internacionais de grande impacto, que devido a isso permite a muitos deles serem reconhecidamente expoentes em suas respectivas áreas, fato é que poucos possuem efetiva compreensão sobre os elementos envolvidos com o ensino pré-universitário, a popularização e a divulgação da Física.

Isso fica explícito quando se faz uma análise do corpo docente das quatro mais importantes instituições públicas, localizadas na região metropolitana da cidade, que formam professores de licenciatura. Nela é possível perceber um panorama que pode lançar um pouco de luz sobre o nível de formação nas IES, visto que o número de profissionais que fazem ou fizeram algum tipo de pesquisa dentro do campo do ensino, mesmo que resultado de apenas uma reflexão, está em torno dos 24\% (UERJ, 2017; UFF, 2018; UFRJ, 2017; UFRRJ, 2017).

Mesmo com o advento dos núcleos docentes estruturantes existentes dentro das unidades responsáveis pelos cursos, instituído pela Lei N. 10.861 (BRASIL, 2004), com o papel de acompanhar, fortalecer e atualizar o projeto pedagógico do curso, o que ocorre é que nem todos os seus membros estão, de alguma forma, sensibilizados com a problemática do ensino. $\mathrm{O}$ pressuposto que alguém formado em Física, sem a devida interação com o segmento do ensino, possa contribuir positivamente com a formação dos alunos, é tão falsa quanto imaginar que um pesquisador em cosmologia possa dar contribuições precisas num laboratório de engenharia de materiais.

É um fato que as contribuições e percepções externas a certo problema são sempre importantes para fomentar a melhoria em qualquer área do conhecimento, pois abrem a possibilidade de evolução da área por uma visão diferenciada. Ainda assim, se essas formações não foram efetivamente preparadas por profissionais conhecedores dos problemas do ensino, é possível que as mudanças necessárias para a melhoria da educação básica nunca ocorram com a qualidade e celeridade esperadas pela sociedade.

\section{Considerações finais}


CRUZ, Frederico Alan de Oliveira; CARVALHO, Paulo Simeão. Reflexões sobre aprendizagem e ensino de física a partir da realidade do Rio de Janeiro.

Dentro do atual cenário educativo, é urgente intervir no sentido de melhorar a formação inicial e continuada dos professores que lecionam os conteúdos de Física nas escolas brasileiras. Fundamentalmente, é necessário que sejam tomadas medidas com o objetivo de melhorar, agilizar e flexibilizar a grade curricular existente dentro das demandas da sociedade atual, aumentar os concursos voltados para a entrada de especialistas nessa área de conhecimento para uma maior presença de professores no curso de formação com sensibilidade na área de ensino e adequar os conteúdos apresentados durante os cursos, permitindo trabalhar a transposição didática dos mesmos para a linguagem do ensino básico.

Finalmente não é possível dissociar o ensino nem do processo avaliativo, nem das novas tendências tecnológicas existentes no mundo contemporâneo. Para tal, deve-se trazer novas ferramentas de ensino e avaliação para a prática pedagógica. Esta ação permitirá que os futuros

professores tenham contato com materiais curriculares, ferramentas e metodologias de ensino e aprendizagem atualizados, para que assim façam uso deles durante a sua futura prática pedagógica, impactando positivamente a educação básica.

\section{Referências}

ABRAMOVAY, Miriam; RUA, Maria das Graças. Violência nas escolas. Brasília: UNESCO Brasil, 2002.

AIZER, Anna. Neighbourhood Violence and Urban Youth. In: NBER Working Paper 13773. Massachusetts, Boston: National Bureau of Economic Research, 2008. Disponível em: <http://www.nber.org/papers/w13773>. Acesso em: 15 jan. 2018.

ALGEBAILE, Eveline Bertino. Escola pública e pobreza: expansão escolar e formação da escola dos pobres no Brasil. 2004. Tese (Doutorado em Educação) - Programa de Pós-Graduação em Educação, Universidade Federal Fluminense, Niterói, 2004.

BELUCE, Andrea Carvalho et al. Compreensão em leitura em universitários: estudo comparativo. In: CONGRESSO NACIONAL DE PSICOLOGIA ESCOLAR E EDUCACIONAL, 10., 2011, Maringá. Anais... Maringá: Universidade Estadual de Maringá, 2011. p. 1-12.

BUABENG, Isaac. Teaching and learning of physics in New Zealand high schools. 2015. Tese (Doutorado em Filosofia da Ciência da Educação) - University of Canterbury, Canterbury, 2015.

BRASIL. Lei no 10.861, de 14 de abril de 2004. Institui o Sistema Nacional de Avaliação da Educação Superior - SINAES e dá outras providências. 2004. Disponível em:

<http://www.planalto.gov.br/ccivil_03/_ato2004-2006/2004/lei/110.861.htm>. Acesso em: 8 maio 2017.

CABRAL NETA, Olimpia. Avaliação da aprendizagem: significados e desafios. In: GOMES, Maria Carmozi de Souza. (Org.). Tecendo saberes e compartilhando experiências sobre avaliação. Natal: EDUFRN, 2006. v. 8. p. 35-48. 
CRUZ, Frederico Alan de Oliveira; CARVALHO, Paulo Simeão. Reflexões sobre aprendizagem e ensino de física a partir da realidade do Rio de Janeiro.

CANTU, Luis; HERRON, James Dudley. Concrete and formal Piagetian stages and science concept attainment. Journal Research in Science Teaching, Champaign, USA, v. 15, n. 2, p. 135-143, mar. 1978.

CARROLL, Brandon R. The effects of school violence and crime on academic achievement. Duke Journal of Economics, North Carolina, v. 18, n. 10, p. 1-33, 2006.

CARVALHO, Paulo Simeão et al. Ensino experimental das ciências: um guia para professores do ensino secundário. 2. ed. Porto, Portugal: Universidade do Porto, 2013.

CARVALHO, Paulo Simeão; CHRISTIAN, Wolfgang; BELLONI, Mario. Physlets e open source physics para professores e estudantes portugueses. Revista Lusófona de Educação, Lisboa, v. 25, n. 25, p. 59-72, 2013.

CARVALHO, Paulo Simeão; PÁRAMOS, Jorge. Pacote interativo e colaborativo: uma forma diferente de ensinar Física. In: PROJETOS de Inovação Pedagógica. Porto, Portugal: Universidade do Porto, 2017. Disponível em: <http://tv.up.pt/videos/nbbiwn-y>. Acesso em: 4 out. 2017.

CAVALLIERI, Fernando; LOPES, Gustavo Peres. Índice de Desenvolvimento Social - IDS: comparando as realidades microurbanas da cidade do Rio de Janeiro. Rio de Janeiro: Secretaria Municipal de Urbanismo, 2008.

.CRUZ, Frederico Alan de Oliveira. Desempenho educacional e renda domiciliar: análise do IDEB dos municípios da Baixada Fluminense. Vivências, Erechim, v. 8, n. 14, p. 92-99, maio 2012.

FREEMAN, Scott et al. Active learning increases student performance in science, engineering, and mathematics. Proceedings of the National Academy of Sciences of the United States of America, Europa, v. 111, p. 8410-8415, 2013.

FREITAS, Sirley Leite; COSTA, Michele Gomes Noé; MIRANDA, Flavine Assis. Avaliação Educacional: formas de uso na prática pedagógica. Revista Meta: Avaliação, Rio de Janeiro, v. 6, n. 16, p. 85-98, jan./abr. 2014.

GROGGER, Jeffrey. Local violence and educational attainment. The Journal of Human Resources, Madison, v. 32, n. 4, p. 659-682, set./nov. 1997.

HOFSTEIN, Avi; LUNETTA, Vincent, N. The role of the laboratory in science teaching: neglected aspects of research. Review of Educational Research, Thousand Oaks, v. 52, v. 2, p. 201-217, jul./set. 1982.

HOFSTEIN, Avi; LUNETTA, Vincent, N. The Laboratory in Science Education: foundations for the twenty-first century. Science Education, Nashville, v. 88, n. 1, p. 28-54, jan. 2004.

HURT, Hallam et al. Exposure to violence: psychological and academic correlates in child witnesses. Archives of Pediatrics and Adolescent Medicine, Ann Arbor, v. 155, n. 12, p. 1351-1356, dez. 2001.

IBGE - Instituto Brasileiro de Geografia e Estatística. Estados@. Rio de Janeiro: IBGE, 2016. Disponível em: <http://www.ibge.gov.br/estadosat/>. Acesso em: 2 maio 2017.

INEP - Instituto Nacional de Estudos e Pesquisas Educacionais Anísio Teixeira. Nota Técnica: Índice de Desenvolvimento da Educação Básica - Ideb. Brasília, DF: INEP, 2007. Disponível em: <https://goo.gl/TMPIEl>. Acesso em: 4 mar. 2017.

INEP - Instituto Nacional de Estudos e Pesquisas Educacionais Anísio Teixeira. IDEB - resultados e metas. Brasília, DF: INEP, 2015a. Disponível em: <http://ideb.inep.gov.br>. Acesso em: 4 mar. 2017.

INEP - Instituto Nacional de Estudos e Pesquisas Educacionais Anísio Teixeira. Enem por escola. Brasília: DF: INEP, 2015b. Disponível em: 〈http://portal.inep.gov.br/web/guest/enem-por-escola〉. Acesso em: 13 jun. 2018. 
CRUZ, Frederico Alan de Oliveira; CARVALHO, Paulo Simeão. Reflexões sobre aprendizagem e ensino de física a partir da realidade do Rio de Janeiro.

KOSER, John F. Active assessment of learning in high school physics. The Physics Teacher, AuburnWashburn, v. 50, n. 8, p. 494-497, out. 2012.

KOPONEN, Ismo T.; MÄNTYLÃ, Terhi. Generative role of experiments in physics and in teaching physics: a suggestion for epistemological reconstruction. Science e Education, Cham, v. 15, n. 1, p. 3154, fev. 2006.

KNIGHT, Randall. Five easy lessons: strategies for successful physics teaching. San Francisco: Addison Wesley, 2004.

LEWIS, Ingrid. A relação entre a água e o saneamento e a educação inclusiva. Londres, Reino Unido: Water Aid, 2009. Disponível em: <http://www.eenet.org.uk/resources/docs/Lewis_IE__WATSANportuguese.pdf >. Acesso em: 2 maio 2017.

LOURENCETTI, Gisela do Carmo. A baixa remuneração dos professores: algumas repercussões no cotidiano da sala de aula. Revista de Educação Pública, Cuiabá, v. 23 n. 52 p. 13-32, jan./abr. 2014.

MAZUR, Eric. Peer instruction: a user's manual. New Jersey: Prentice Hall, 1997.

MEGID NETO, Jorge; FRACALANZA, Hilário. O livro didático de ciências: problemas e soluções. Ciência e Educação, Bauru, v. 9, n. 2, p. 147-157, 2003.

MENEGHEL, Stela Maria; KREISCH, Cristiane. Concepções de avaliação e práticas avaliativas na escola: entre possibilidades e dificuldades. In: CONGRESSO NACIONAL DE EDUCAÇÃO EDUCERE / III Encontro Sul Brasileiro de Psicopedagogia, 9., 2009, Curitiba, PR. Anais... Curitiba: EDUCERE, 2009. p. 9818-9831.

MHILIWA, Joseph Anthon. The effects of school location on learner's academic performance: a case of community secondary schools in Makambako Town Council, Njombe. 2015. Dissertação (Mestrado em Educação) - Programa of Administration, Planning and Policy Studies, The Open University of Tanzania, Dar es Salaam, Tanzânia, 2015.

MONTEIRO, Vitor Borges; ARRUDA, Elano Ferreira. O impacto da violência urbana nos indicadores de evasão escolar na região metropolitana de Fortaleza. In: CONFERÊNCIA DO DESENVOLVIMENTO (CODE) / I Circuito de Debates Acadêmicos, 2., Brasília, DF. Anais... Brasília: CODE, 2011.

MONTEIRO, Jéssica de Sousa; SILVA, Diogo Pereira. A influência da estrutura escolar no processo de ensino-aprendizagem: uma análise baseada nas experiências do estágio supervisionado em Geografia.

Geografia Ensino e Pesquisa, Santa Maria, v. 19, n.3, p. 19-28, set./dez. 2015.

NOVAK, Gregor M. et al. Just-in-Time teaching: blending active learning with web technology. New Jersey: Prentice Hall, 1999.

OCDE - Organização para a Cooperação e Desenvolvimento Econômico. Brasil no PISA 2015: análises e reflexões sobre o desempenho dos estudantes brasileiros. São Paulo: Fundação Santillana, 2016.

PAZ, Fabio Soares. A prática docente do professor de física: percepções do formador sobre o ensino. 2014. Dissertação (Mestrado em Educação) - Programa Pós-Graduação em Educação, Universidade Federal do Piauí, Teresina, 2014.

PERRY, Caroline. News \& Events: educating the innovators, Cambridge, may. 2013. Disponível em: <https://www.seas.harvard.edu/news/2013/05/educating-innovators>. Acesso em: 7 jun. 2017.

PINA, Paula Priscila Gomes do Nascimento. A relação entre o ensino e o uso do livro didático de geografia. 2009. Dissertação (Mestrado em Geografia) - Programa de Pós-Graduação em Geografia, Universidade Federal da Paraíba, João Pessoa, 2009. 
CRUZ, Frederico Alan de Oliveira; CARVALHO, Paulo Simeão. Reflexões sobre aprendizagem e ensino de física a partir da realidade do Rio de Janeiro.

QUINTAS, Maria José; CARVALHO, Paulo Simeão. Ensino interativo na abordagem de eletricidade numa escola portuguesa. Caderno Brasileiro de Ensino de Física, Santa Catarina, v. 33, n. 3, p. 839-860, dez. 2016.

RAFAEL, Rosane Cordeiro; ESCHER, Marco Antônio. Evasão, baixo rendimento e reprovações em cálculo diferencial e integral: uma questão a ser discutida. In: ENCONTRO MINEIRO DE EDUCAÇÃO MATEMÁTICA. 7., 2015, São João Del-Rei. Anais... São João Del-Rei, UFJF, 2015. p. 1-12.

RAUTH, Viviane Maria. Implicações do programa ensino médio inovador no ensino de biologia, física e química nas escolas estaduais de Curitiba. 2015. Dissertação (Mestrado em Educação em Ciências e em Matemática) - Programa de Pós-Graduação em Educação em Ciências e em Matemática, Universidade Federal do Paraná, Curitiba, 2015.

REDISH, Edward. Teaching physics with the physics suite. New Jersey: John Wiley \& Sons Inc., 2003. RIO DE JANEIRO. CMRJ - Câmara Municipal do Rio de Janeiro. ANEXO III. 2009. Disponível em: <http://www.camara.rj.gov.br/planodiretor/pd2009/saudepd/Anexo3_IDH.pdf>. Acesso em: 13 jun. 2018.

RISSI, Marinalva Calabrez; MARCONDES, Martha Aparecida Santana. (Org.). Estudo sobre a reprovação e retenção nos Cursos de Graduação - 2009. Londrina: UEL, 2011.

SCRIPTORE, Juliana Souza; AZZONI, Carlos Roberto; MENEZES FILHO, Naércio Aquino. Saneamento básico e indicadores educacionais no Brasil. Working Paper Series - USP, São Paulo, n. 28, 2015. p. 1-34.

SERZEDELLO, Marcos. Física!? Isso pra mim é grego! História e filosofia da física: dos présocráticos a Newton. São José do Rio Preto: Grupo HN, 2012.

SHAYER, Michael; ADEY, Philip. Towards a science of science teaching: cognitive development and curriculum demand. London: Heinemann Educational Books, 1981.

SOKOLOFF, David; THORNTON, Ron; LAWS, Priscila. Real Time Physics - Active Learning Laboratories. New Jersey: John Wiley \& Sons, Inc., 1999-2004. Modules 1-4.

SWEET, Michael; PELTON-SWEET, Laura. The social foundation of team-based learning: students accountable to students. New Directions for Teaching and Learning. New Jersey: John Wiley \& Sons, 2008. p. 29-40.

UERJ - Universidade do Estado do Rio de Janeiro. Instituto de Física Armando Dias Tavares. Rio de Janeiro: UERJ, 2017. Disponível em: 〈https://goo.gl/pkaSVE〉. Acesso em: 10 maio 2017.

UFF - Universidade Federal Fluminense. Grade e corpo docente. Niterói: UFF, 2018. Disponível em: <https://goo.gl/8AXgHK>. Acesso em: 13 jul. 2018.

UFRJ - Universidade Federal do Rio de Janeiro. Instituto de Física. Rio de Janeiro: UFRJ, 2017.

Disponível em: 〈https://goo.gl/uRi3B8>. Acesso em: 10 maio 2017.

UFRRJ - Universidade Federal Rural do Rio de Janeiro. Departamento de Física. Seropédica, RJ: UFRRJ, 2017. Disponível em: <https://goo.gl/tebdz9>. Acesso em: 10 maio 2017.

ZANOTELLO, Marcelo; ALMEIDA, Maria José Pereira Monteiro. Produção de sentidos e possibilidades de mediação na física do ensino médio: leitura de um livro sobre Isaac Newton. Revista Brasileira de Ensino de Física, São Paulo, v. 29, n. 3, p. 437-446, 2007. 
CRUZ, Frederico Alan de Oliveira; CARVALHO, Paulo Simeão. Reflexões sobre aprendizagem e ensino de física a partir da realidade do Rio de Janeiro.

Frederico Alan de Oliveira Cruz

Universidade do Porto | Departamento de Física e Astronomia,

IFIMUP, Faculdade de Ciências. Porto | Portugal.

Universidade Federal Rural do Rio de Janeiro | Instituto de

Ciências Exatas, Departamento de Física

Seropédica | RJ | Brasil. Contato: frederico@ufrrj.br

ORCID 0000-0002-2612-3952

Paulo Simeão de Carvalho

Universidade do Porto | Unidade de Ensino das Ciências /

Departamento de Física e Astronomia, IFIMUP, Faculdade de

Ciências.

Porto | Portugal. Contato: psimeao@fc.up.pt

ORCID 0000-0002-5381-955X

Artigo recebido em: 26 mar. 2018 e aprovado em: 24 abr. 2018. 